\title{
Tribal Odisha Eye Disease Study (TOES \# 2) Rayagada school screening program: efficacy of multistage screening of school teachers in detection of impaired vision and other ocular anomalies
}

This article was published in the following Dove Press journal:

Clinical Ophthalmology

\author{
Lapam Panda' \\ Taraprasad Das' \\ Suryasmita Nayak' \\ Umasankar Barik ${ }^{2}$ \\ Bikash C Mohanta' \\ Jachin Williams ${ }^{3}$ \\ Vivekanand Warkad ${ }^{4}$ \\ Guha Poonam Tapas Kumar ${ }^{5}$ \\ Rohit C Khanna ${ }^{3}$ \\ 'Indian Oil Center for Rural Eye \\ Health, GPR ICARE, LV Prasad Eye \\ Institute, MTC Campus, Bhubaneswar, \\ India; ${ }^{2}$ Naraindas Morbai Budhrani \\ Eye Centre, LV Prasad Eye Institute, \\ Rayagada, India; ${ }^{3}$ Gullapalli Pratibha \\ Rao International Center for \\ Advancement of Rural Eye Care, \\ LV Prasad Eye Institute, KAR \\ Campus, Hyderabad, India; ${ }^{4}$ Miriam \\ Hyman Children Eye Care Center, \\ LV Prasad Eye Institute, MTC \\ Campus, Bhubaneswar, India; ${ }^{5}$ District \\ Administration, Government of \\ Odisha, Rayagada, India
}

Correspondence: Taraprasad Das L V Prasad Eye Institute, Road \# 2, Banjara Hills, Hyderabad 500 034, India Email tpd@lvpei.org
Purpose: To describe program planning and effectiveness of multistage school eye screening and assess accuracy of teachers in vision screening and detection of other ocular anomalies in Rayagada District School Sight Program, Odisha, India.

Methods: This multistage screening of students included as follows: stage I: screening for vision and other ocular anomalies by school teachers in the school; stage II: photorefraction, subjective correction and other ocular anomaly confirmation by optometrists in the school; stage III: comprehensive ophthalmologist examination in secondary eye center; and stage IV: pediatric ophthalmologist examination in tertiary eye center. Sensitivity, specificity, positive predictive value (PPV) and negative predictive value (NPV) of teachers for vision screening and other ocular anomaly detection were calculated vis-à-vis optometrist (gold standard).

Results: In the study, 216 teachers examined 153,107 (95.7\% of enrolled) students aged $5-15$ years. Teachers referred 8,363 (5.4\% of examined) students and 5,990 ( $71.6 \%$ of referred) were examined in stage II. After prescribing spectacles to 443, optometrists referred 883 students to stage III. The sensitivity (80.51\%) and PPV (93.05\%) of teachers for vision screening were high, but specificity (53.29\%) and NPV (26.02\%) were low. The specificity and NPV, in general, were higher in ocular anomaly detection but varied from disease to disease.

Conclusion: Multistage school screening is rapid and comprehensive in a resource-limited community. Regular training and periodic reinforcement of teachers for vision assessment and other ocular anomaly identification are required for further success of the strategy.

Keywords: vision screening, school children, sensitivity, specificity, tribal, ocular anomalies

\section{Introduction}

The eastern Indian state of Odisha is home for $9.7 \%$ of the tribal population of the country. At 8,140,000 people, the tribal population in Odisha was $22.1 \%$ of the total population in 2011 census. It exceeded $50 \%$ of the total population in 4 of 30 districts of Odisha; they were Malkangiri (57.4\%), Rayagada (55.8\%), Nabrangpur (55\%), and Mayurbhanj (56.6\%). ${ }^{1}$ The tribal people live in remote areas with poor access to health and education. The Tribal Odisha Eye Disease Study is the evaluation of various eye health aspects of people from the tribal districts of Odisha. The current report is part of this study.

School eye health survey is a time-tested method to screen students for refractive error. ${ }^{2-4}$ It is the second largest program under the National Program for Control of Blindness in India after cataract surgery ${ }^{5,6}$ and is currently a priority of Rashtriya 
Bala Swasthya Karyakram (National Child Health Program) of the Government of India. But the task is not easy due to large number of students, and lack of trained ophthalmic personnel, worse in hilly and remote terrain like Rayagada district, Odisha state, India. The Rayagada School Sight Program (SSP) was designed to examine all students attending schools in the district. In order to overcome the human resource constraint, we designed the program in 4 stages. The program also used a rapid objective refraction system, the photorefraction. This study assessed the effectiveness of the program and the accuracy of teachers for vision screening and detection of other ocular anomalies vis-à-vis the optometrists.

\section{Methods}

The Rayagada SSP was a multistage cross-sectional descriptive and analytical study done between August 2016 and June 2017. The study included all students of either gender but excluded the ones with contagious diseases (such as scabies diagnosed by physician) and those absent on the days of examination. The older students ( $\geq 16$ years of age) were excluded. The study was approved by the local district administration (Rayagada, Odisha) and ethics committee of $\mathrm{L} \mathrm{V}$ Prasad Eye Institute, Bhubaneswar, India (2016-15-CB-14). The research protocol adhered to the provision of the Declaration of Helsinki for research involving human beings. The school authorities provided consent for eye examination by optometrists in their premises. Written informed consent was obtained from the parents of the children who were referred for examination by ophthalmologist in the hospital.

The study was done in 4 stages: stage I: screening by the trained school teachers in the school; stage II: photorefraction, optometrist examination, and subjective correction by optometrist in the school; stage III: cycloplegic-refraction and comprehensive ophthalmologist examination in secondary eye center; and stage IV: surgery and visual rehabilitation by pediatric ophthalmologist in tertiary eye center.

\section{Stage I. A.Teacher training and screening strategy}

The local administration selected teachers from the pool of teachers available in the district depending on the location for the screening program. Male teachers were preferred because of the travel logistics in this difficult hilly terrain. Optometrist (SN) and public health personnel (BCM and JW) imparted 1-day teachers training at Rayagada-based secondary eye center. The training consisted of recording vision by using Snellen E chart, basic eye anatomy, and common eye disorders (such as red eye, white shining deposits suggestive of Bitot spot). At conclusion, teachers were provided with a screening kit that contained a measuring tape, flashlight, an illustrative booklet, and a spreadsheet for data entry.

The district administration divided schools into clusters and each teacher was given a fixed area for screening.

\section{Stage I. B. Screening by school teachers}

Each screening day in the school started after a brief description of the methodology of vision testing. All location and demographic details of students were entered in the spreadsheet. Students already wearing spectacles were identified. The school teachers screened for vision using Snellen's E chart of 3 lines, for testing vision of 20/60, 20/40, and 20/30. Vision in each eye was tested separately (with spectacles, if any), at $6 \mathrm{~m}$. If the child was able to read the last line (20/30), it was marked "pass" denoted by " 1 "; if not able to, it was marked "fail" denoted by " 0 "; and if uncooperative for vision testing, it was marked "uncooperative" denoted by "99". An external eye flashlight examination and a Hirschberg test ${ }^{7}$ followed the vision testing and a specific number, 0-9, was assigned for various identified causes (Table 1).

Students with presenting visual acuity (PVA) $<20 / 30$, uncooperative students, and those detected to having any ocular anomaly were referred.

\section{Stage 2. Photorefraction and optometrist examination}

Stage 2 was done in the school premises. The following sequence was maintained: measurement of the PVA, ocular motility, Hirschberg test, cover-uncover test, flashlight examination of the anterior segment, refraction by photoscreener (Spot ${ }^{\mathrm{TM}}$, Welch Allyn, Skaneateles Falls, NY, USA) and subjective refraction. Presenting vision was tested for each eye (with spectacles if any) by placing the vision chart

Table I Assignments in school screening

\begin{tabular}{ll}
\hline Denotation & Signs and symptoms \\
\hline 0 & Squint \\
1 & Eye lid problem \\
2 & Bitot spot \\
3 & Night blindness \\
4 & Redness (with watering and discharge) \\
5 & Injury \\
6 & Eye swelling \\
7 & Corneal problem \\
8 & Cataract \\
9 & Other \\
\hline
\end{tabular}


at $6 \mathrm{~m}$ distance. The subjective correction was done by placing the appropriate lenses in the trial frame and testing the vision with the chart placed at $6 \mathrm{~m}$.

Trained community workers did the photorefraction. The instrument was held at a $1 \mathrm{~m}$ distance at the eye level of the subject. The subject was asked to look at the target inside the screener; the device was moved in a manner that the examiner captured both the eyes on the screen. As per the manufacturer, the Spot screener is capable of detecting refractive error between $-7.5 \mathrm{D}$ and $+7.5 \mathrm{D}$, and the system notifies when it is beyond this range. Following photorefraction, the students were referred in 3 situations - when the photorefraction value was beyond $+2 \mathrm{D}$, beyond $-7.5 \mathrm{D}$ (high myopes), and not recordable. Photoscreener $>+2 \mathrm{D}$ were referred for cyclo-refraction as studies have shown the possibilities of underestimation by photoscreener in hyperopia beyond this range. ${ }^{8-10}$

\section{Subjective correction}

It was done by the optometrist using the E-chart for those having vision $<20 / 20$ in 1 or both eyes and photoscreener value between $-7.5 \mathrm{D}$ and $+2 \mathrm{D}$. The photoscreener suggested values for subjective correction were used and the spectacles were prescribed only when vision improved to $20 / 20$ in both eyes. Those who had vision $<20 / 20$ after photoscreener suggested subjective correction were referred. Those having any ocular anomalies were referred irrespective of the vision and photoscreener finding.

\section{Phase III. Comprehensive ophthalmologist examination}

The referred children received a detailed eye examination in the hospital by a comprehensive ophthalmologist (LP). This included visual acuity measurement using COMPlog system (London, UK), repeated photorefraction, dry refraction using a retinoscope (Heine, Germany), cover-uncover test, slit-lamp examination (Carl Zeiss, Göttingen, Germany), followed by post dilation cyclo-refraction, and indirect ophthalmoscopic examination (Heine, Germany). Spectacles and medical treatment were given as per the need. Children who needed surgery were referred to the pediatric ophthalmologist (VW) (stage IV).

\section{Data entry and analysis}

The data were entered into Microsoft excel 2016 database. Data were double checked on the day of entry. The school screening effectiveness was compared with the parameters laid down by Limburg et al. ${ }^{2}$ The accuracy of teachers in vision screening and ocular anomaly detection were compared with findings of the optometrist where the latter was considered the gold standard. Sensitivity, specificity, positive predictive value (PPV) and negative predictive value (NPV) were calculated. Children referred by teachers only for ocular anomaly (presumably with normal vision) received a repeat vision testing by the optometrist to determine the specificity and NPV for vision screening; the children referred only for vision problem (presumably no ocular anomaly) received a comprehensive eye examination by the optometrists to determine the specificity and NPV for ocular anomaly detection by the teachers. The children referred for both vision problem and ocular anomaly were examined by optometrists to determine the sensitivity and PPV. The $p$-value for inter-age and inter-gender difference were calculated by chi square test and $p$-value $<0.05$ was considered significant.

\section{Results}

The Rayagada district has a population of 1,099,827 living in 11 blocks. ${ }^{11}$ It has 2,124 schools and 164,374 students ( $16.9 \%$ of the total population) are admitted to these schools. We trained 216 teachers (213 male). The schools were divided into 125 clusters depending on the location and the class size. Two teachers each were deployed in 91 school clusters and 1 teacher each was deployed in remaining 34 school clusters; after excluding 4,389 students (specified earlier), 159,985 were enrolled for the study. Finally, 153,107 (95.7\% of enrolled - 77,837 male, 50.83\%; 75,270 female, $49.16 \%)$ students were screened in the program. The mean age of students was 9.3 \pm 2.7 (range 5-15) years and 2,044 (1.3\% of screened) were wearing spectacles. Stage I was completed in 36 days.

Teachers referred 8,363 (5.4\% of screened) students for the following 3 reasons $-3,844$ for poor PVA $(<20 / 30)$, 3,433 for other ocular anomalies, and 1,086 for both. A total of 5,990 (71.6\% of referred) were examined in the Phase II - 3,049 for poor PVA (presumably no ocular anomaly), 1,970 for ocular anomaly (presumably with normal vision), and the remaining 971 for both. The optometrist reexamined all children detected to have no ocular anomaly (with poor PVA) $(n=3,049)$ and the children detected to have normal vision (with ocular anomaly) $(n=1,970)$ by the teachers for calculations of specificity and NPV of ocular anomaly and visual acuity detection, respectively. The stage II was completed in 47 working days. A total of 883 students were referred to stage III. (Figure 1) Table 2 shows the effectiveness of school screening as per Limburg et al. ${ }^{2}$ 


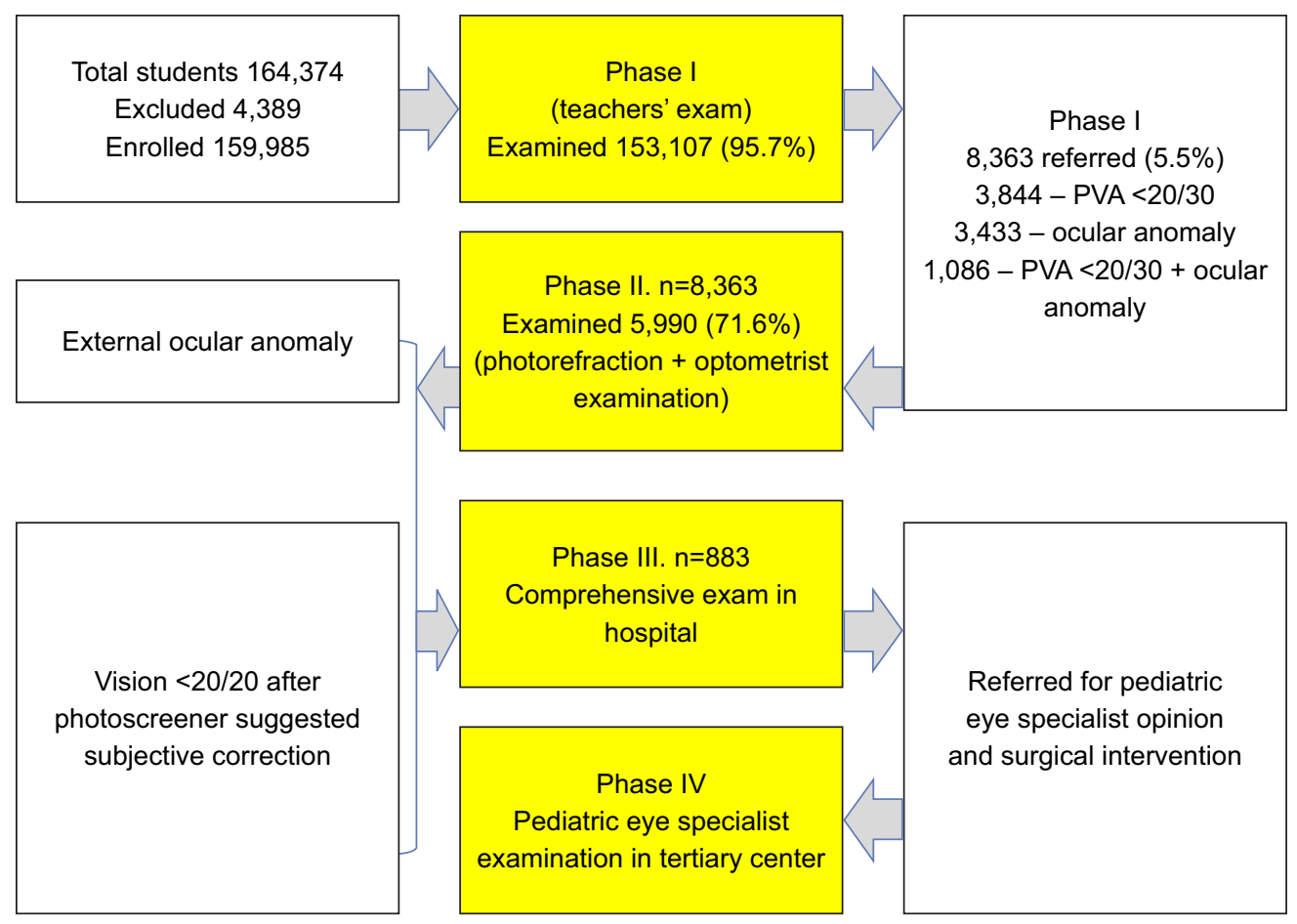

Figure I Patient flow in multistage school screening. Abbreviation: PVA, presenting visual acuity.

Accuracy calculation was based on PVA of 20/30 or worse in the right eye. Compared with optometrists, the sensitivity of teachers in identifying students with impaired vision was $80.51 \%$ and the specificity was $53.29 \%$ (teachers erroneously identified problem in $46.71 \%$ students). The PPV (agreement of abnormality by teachers and optometrists) was $93.05 \%$. NPV (agreement of "normal" by teachers and optometrists) was $26.02 \%$. (Table 3 ).

Sensitivity of vision testing was more in male children (trend) and was more specific in older age group children with a statistically significant difference $(p<0.05)$. In the detection of ocular anomalies, specificity and NPV were comparatively high with cataract, $98.74 \%$ and $99.71 \%$, respectively.
The sensitivity and PPV were low (Table 4). Strabismus had highest sensitivity $(31.45 \%)$ and PPV (25.64\%). Cataract had lowest sensitivity (5.56\%) and Bitot's spot had lowest PPV (0.67\%).

\section{Discussion}

The primary advantages of multistage screening were the speed and effective utilization of skilled manpower. Because teachers were involved after a brief training, stage I was completed in 36 working days. Because rapid refraction (photorefraction) was used by a trained community worker, optometrist's time was more effectively used for subjective correction and detection of other ocular anomalies.

Table 2 Effectiveness of our school screening as per Limburg et al ${ }^{2}$

\begin{tabular}{|c|c|c|c|c|c|c|}
\hline \multicolumn{2}{|c|}{ Parameter } & \multirow{2}{*}{$\begin{array}{l}\begin{array}{l}\text { This } \\
\text { study }\end{array} \\
2,124 \\
\end{array}$} & \multirow{2}{*}{$\begin{array}{l}\text { Indicator } \\
\text { Coverage, organization }\end{array}$} & \multirow{2}{*}{$\begin{array}{l}\text { Formula } \\
\text { b/a }\end{array}$} & \multirow{2}{*}{$\begin{array}{l}\begin{array}{l}\text { Controlled } \\
\text { program }\end{array} \\
\text { One teacher }\end{array}$} & \multirow{2}{*}{$\begin{array}{l}\text { This study } \\
\text { One teacher }\end{array}$} \\
\hline a & No of schools in area & & & & & \\
\hline b & No of teachers trained & 216 & & & per school & for 10 schools \\
\hline c & No of children enrolled & 159,985 & Coverage, organization & $d / c$ & $80 \%-100 \%$ & $95.7 \%$ \\
\hline$d$ & No of children screened & 153,107 & & & & \\
\hline e & No of children referred & 8,363 & $\begin{array}{l}\text { Quality training/quality } \\
\text { screening }\end{array}$ & $\mathrm{e} / \mathrm{d}$ & $5 \%-10 \%$ & $5.4 \%$ \\
\hline$f$ & $\begin{array}{l}\text { No of children examined } \\
\text { by optometrist }\end{array}$ & 5,990 & $\begin{array}{l}\text { Organization refraction } \\
\text { services faith }\end{array}$ & $f / e$ & $60 \%-90 \%$ & $71.6 \%$ \\
\hline$g$ & $\begin{array}{l}\text { No of children referred } \\
\text { to ophthalmologist }\end{array}$ & 883 & $\begin{array}{l}\text { Confidence of } \\
\text { optometrist/faith }\end{array}$ & $g / f$ & $10 \%-20 \%$ & $14.7 \%$ \\
\hline
\end{tabular}


Table 3 Sensitivity, specificity, and predictive values of the school teachers for visual acuity

\begin{tabular}{|c|c|c|c|c|}
\hline & Sensitivity; \% (95\% CI) & Specificity; \% (95\% CI) & PPV; \% (95\% CI) & NPV; \% (95\% Cl) \\
\hline Total & $80.5 \mathrm{I}$ (79.35 to $8 \mathrm{I} .6 \mathrm{I})$ & 53.29 (49.32 to 57.22$)$ & 93.05 (92.23 to 93.79$)$ & 26.02 (23.66 to 28.53$)$ \\
\hline Male & 81.59 (79.99 to 83.09$)$ & 52.68 (47.02 to 58.28$)$ & 93.29 (92.13 to 94.28$)$ & 26.21 (22.85 to 29.88$)$ \\
\hline Female & 79.39 (77.70 to 80.98$)$ & 53.87 (48.3I to 59.34$)$ & 92.81 (91.59 to 93.86$)$ & 25.85 (22.62 to 29.36$)$ \\
\hline $\begin{array}{l}p \text {-value for inter-gender } \\
\text { difference }\end{array}$ & 0.0565 & 0.7689 & 0.5466 & 0.8851 \\
\hline Aged $5-10$ years & 80.93 (79.30 to 82.47$)$ & 48.28 (42.28 to 54.32$)$ & 93.39 (92.22 to 94.28$)$ & 21.91 (18.72 to 25.47$)$ \\
\hline Aged II-15 years & 80.08 (78.43 to 81.64$)$ & $57.06(51.80$ to 62.16$)$ & $92.72(91.5 \mathrm{I}$ to 93.77$)$ & 29.55 (26.22 to 33.12$)$ \\
\hline $\begin{array}{l}p \text {-value for inter-age } \\
\text { difference }\end{array}$ & 0.4609 & $0.0319^{a}$ & 0.3996 & $0.0022^{\mathrm{a}}$ \\
\hline
\end{tabular}

Note: aSignificant.

Two optometrists could complete stage II in 47 working days. We anticipate further advancement and refinement of the technology in the coming years.

The sensitivity for vision screening at $80.51 \%$ was higher than some studies ${ }^{4,12,13,16,18,19}$ and lower than few others. ${ }^{14,15,17,20}$ PPV at $93.05 \%$ was higher than other studies..$^{13,14,16,17}$ Specificity and NPV were $53.29 \%$ and $26.02 \%$, respectively; this was lower compared with $70.8 \%-99.2 \%$ specificity $^{4,11-19}$ and 95.7\%-99\% NPV in other studies. . $^{13,14,16,17,20}$ High sensitivity and PPV signifies that most of the students with impaired vision were detected by the teachers. This is a good sign. But low specificity and NPV signifies that the teachers were unprepared to take any risk of missing impaired vision. This resulted in referral of many normal children that impacted the program cost and the burden.

The sensitivity of vision screening was more in male children. Specificity was higher with older age, similar to an earlier report. ${ }^{21}$ Contrary to couple of reports, we did not notice a statistically significant decreased sensitivity with age. ${ }^{16,21}$

The specificity and NPV for ocular anomaly detection were comparatively high with cataract, $98.74 \%$, and $99.71 \%$, respectively. Thus, normal students were not referred unnecessarily. But the sensitivity and PPV were low. Detection of strabismus had highest sensitivity (31.45\%), followed by eyelid anomalies (10.71\%) and corneal problems (10.23\%). Similarly, strabismus had highest PPV (25.64\%) followed by corneal problems $(6.98 \%)$. This probably owes to the gross deviations, eyelid anomalies, and large visible corneal scars. Since Bitot's spot was a trivial sign, the school teachers missed the same; it had very low sensitivity $(6.06 \%)$ and the least PPV (0.67\%). Cataract also had least sensitivity (5.56\%) and it might be due to difficulty in detection in a well-lit screening site. Despite this major disadvantage, teachers detected few ocular anomalies without additional expenditure of additional time and resources. This could have been missed if measurement of vision would have been the only focus. Hence, we suggest that screening by teachers should include detection of ocular anomalies also. We are unable to comment on the reasons for inter-age and inter-gender difference in few ocular anomalies.

Reasons for low specificity and NPV for vision screening and low sensitivity and PPV for ocular anomaly detection could include: 1) 1-day training of the teachers in both vision screening and ocular abnormality detection was probably insufficient; 2) screening by the selected teachers versus all teachers (screening by all teachers is shown to be more efficacious ${ }^{22}$ ); 3 ) insufficient number of assigned teachers versus 1 teacher per school (Limburg et al suggested at least 1 teacher per school ${ }^{2}$ ); 4) assignment of male teachers contrary to suggested female class teachers wearing spectacles; ${ }^{2}$ ) using 20/30 as the cutoff vision by teachers contrary to few others who used $20 / 40$ as cutoff ${ }^{14,15,17,19}$ (in our opinion, students would have difficulty reading if

Table 4 Accuracy of school teachers in the detection of other ocular anomalies

\begin{tabular}{|c|c|c|c|c|}
\hline Diagnosis & Sensitivity; \% (95\% CI) & Specificity; \% (95\% CI) & PPV; \% (95\% CI) & NPV; \% (95\% CI) \\
\hline Strabismus & 31.45 (24.74 to 39.03$)$ & 97.5। (97.08 to 97.88) & $25.64(20.02$ to 32.20$)$ & 98.12 (97.74 to 98.44$)$ \\
\hline Eye lid problem & I0.7I (5.74 to 19.12) & 97.53 (97.10 to 97.89$)$ & 5.81 (3.08 to 10.67$)$ & 98.71 (98.39 to 98.97) \\
\hline Bitot's spot & 6.06 (1.68 to 19.6I) & $95.00(94.4 I$ to 95.52$)$ & $0.67(0.18$ to 2.40$)$ & 99.46 (99.23 to 99.62$)$ \\
\hline Cornea problem & $10.23(5.47$ to $18.3 \mathrm{I})$ & 97.97 (97.57 to 98.30$)$ & 6.98 (3.7I to I2.73) & $98.65(98.32$ to 98.92$)$ \\
\hline Cataract & $5.56(0.99$ to 25.76$)$ & 98.74 (98.43 to 99.00$)$ & I.32 (0.23 to 7.08$)$ & 99.7I (99.54 to 99.82) \\
\hline Other $^{\mathrm{a}}$ & 31.44 (27.70 to 35.70$)$ & 55.88 (54.56 to 57.19$)$ & $6.28(5.4 \mathrm{I}$ to 7.28$)$ & 89.74 (88.68 to $90.7 \mathrm{I})$ \\
\hline
\end{tabular}

Note: a Other includes redness, injury, and eye swelling, etc. 
their PVA is $<20 / 30$ ); and 6) unfamiliarity of the teachers to the program, this being the first school eye screening of this magnitude in the district.

Screening by optometrist and community workers is a definite option ${ }^{2,3,23}$ though screening by teachers is easier in terms of compliance of the students, continuity of the program over years, and overall low opportunity cost. Additionally, teachers could better motivate children for subsequent visit to ophthalmic personnel and monitor the impact of treatment on their performance in studies.

In view of the severe shortage of trained manpower in eye care, ${ }^{24,25}$ use of teachers appears a better choice for this program. The teachers should be given an annual training with periodic assessment to increase the efficacy. It is prudent to train all teachers rather than selected teachers. This will also avoid the travel logistics. Taking into account the difference in geography and socioeconomic condition, the data cannot be extrapolated to the entire country, but due to the systematic methodology and effectiveness, it is replicable in the other tribal districts of the state.

\section{Conclusion}

Multistage screening is time- and cost-effective in resourceconstraint setting. Assessment of efficacy of teachers in detection of other ocular anomalies besides impaired vision was done for the first time by us (PubMed search); we suggest that detection of ocular anomaly beyond refractive error should be an integral part of all program. Teachers need more training and regular evaluation for better efficacy. Our study could act as a guide for program planning to address correctable visual impairment and other ocular anomalies in children.

\section{Acknowledgment}

This study was supported by Hyderabad Eye Research Foundation.

\section{Disclosure}

The authors report no conflicts of interest in this work.

\section{References}

1. Directorate of Field Publicity Bhubaneswar. Census of Odisha. Available from: http://www.dfp.nic.in/bhubaneswar/Census.aspx. Accessed June 24, 2017.

2. Limburg H, Kansara HT, d'Souza S. Results of school eye screening of 5.4 million children in India-a five-year follow-up study. Acta Ophthalmol Scand. 1999;77(3):310-314.

3. Jose R, Sachdeva S. School eye screening and the National Program for Control of Blindness. Indian Pediatr. 2009;46(3):205-208.

4. Limburg H, Vaidyanathan K, Dalal HP. Cost-effective screening of schoolchildren for refractive errors. World Health Forum. 1995;16(2):173-178.

5. Vijayalakshmi P, Miralidhar R. Extent and impact of eye disease in children in India and the status of paediatric service delivery. Community Eye Health J. 2010;23(72):5127-5128.
6. Sudhan A, Pandey A, Pandey S, Srivastav P, Pandey KP, Jain BK. Effectiveness of using teachers to screen eyes of school going children in Satna district of Madhya Pradesh, India. Indian J Ophthalmol. 2009; 57(6):455-458.

7. Wright KW, Strube YN, editors. Pediatric Ophthalmology and Strabismus. 3rd ed. New York, NY, USA: Oxford University Press; 2012: 217-264.

8. Paff T, Oudesluys-Murphy AM, Wolterbeek R, et al. Screening for refractive errors in children: the plusoptiX S08 and the Retinomax K-plus2 performed by a lay screener compared to cycloplegic retinoscopy. J AAPOS. 2010;14(6):478-483.

9. Payerols A, Eliaou C, Trezeguet V, Villain M, Daien V. Accuracy of PlusOptix A09 distance refraction in pediatric myopia and hyperopia. BMC Ophthalmol. 2016;16:72.

10. Yan XR, Jiao WZ, Li ZW, Xu WW, Li FJ, Wang LH. Performance of the Plusoptix A09 photoscreener in detecting amblyopia risk factors in Chinese children attending an eye clinic. PLoS One. 2015;10(6): e0126052.

11. Rayagada Demographics, District Level Information of Rayagada|Odisha [webpage on the Internet]. Districts of india.com. 2018 [cited January 29, 2018]. Available from: https://www.districtsofindia.com/odisha/ rayagada/demographics/index.aspx. Accessed January 29, 2018.

12. Saxena R, Vashist P, Tandon R, Pandey RM, Bhardawaj A, Menon V. Accuracy of visual assessment by school teachers in school eye screening program in Delhi. Indian J Community Med. 2015;40(1):38-42.

13. Khandekar R, Al Harby S, Abdulmajeed T, Helmi SA, Shuuaili IS. Validity of vision screening by school nurses in seven regions of Oman. East Mediterr Health J. 2004;10(4-5):528-536.

14. Sharma A, Li L, Song Y, et al. Strategies to improve the accuracy of vision measurement by teachers in rural Chinese secondary schoolchildren: Xichang Pediatric Refractive Error Study (X-PRES) report no. 6. Arch Ophthalmol. 2008;126(10):1434-1440.

15. Sabri K, Thornley P, Waltho D, et al. Assessing accuracy of non-eye care professionals as trainee vision screeners for children. Can J Ophthalmol. 2016;51(1):25-29.

16. OstadiMoghaddam H, Fotouhi A, Hashemi H, et al. Validity of vision screening tests by teachers among school children in Mashhad, Iran. Ophthalmic Epidemiol. 2012;19(3):166-171.

17. Paudel P, Kovai V, Naduvilath T, Phuong HT, Ho SM, Giap NV. Validity of teacher-based vision screening and factors associated with the accuracy of vision screening in Vietnamese children. Ophthalmic Epidemiol. 2016;23(1):63-68.

18. Kaur G, Koshy J, Thomas S, Kapoor H, Zachariah JG, Bedi S. Vision screening of school children by teachers as a community based strategy to address the challenges of childhood blindness. J Clin Diagn Res. 2016;10(4):NC09-NC14.

19. Teerawattananon K, Myint CY, Wongkittirux K, et al. Assessing the accuracy and feasibility of a refractive error screening program conducted by school teachers in pre-primary and primary schools in Thailand. PLoS One. 2014;9(6):e96684.

20. Spowart KM, Simmers A, Tappin DM. Vision testing in schools: an evaluation of personnel, tests, and premises. J Med Screen. 1998;5(3): 131-132.

21. Chui L, Fraser T, Hoar K, LaRoche GR. Negative predictive value of a vision screening program aimed at children aged 3 to 4 years old. J AAPOS. 2004;8(6):566-570.

22. Priya A, Veena K, Ravilla T, et al. Vision screening by teachers in Southern Indian schools: testing a new "All Class Teacher" model. Ophthalmic Epidemiol. 2015;22(1):60-65.

23. Marmamula S, Khanna RC, Mettla AL, et al. Agreement and diagnostic accuracy of vision screening in children by teachers, community eyehealth workers and vision technicians. Clin Exp Optom. Epub 2017 Jun 28.

24. Dandona R. Optometry and eye care in India. Indian J Ophthalmol. 1998;46:175.

25. Desai S, Desai R, Desai NC, Lohiya S, Bhargava G, Kumar K. School eye health appraisal. Indian J Ophthalmol. 1989;37(4):173-175. 
Clinical Ophthalmology

\section{Publish your work in this journal}

Clinical Ophthalmology is an international, peer-reviewed journal covering all subspecialties within ophthalmology. Key topics include: Optometry; Visual science; Pharmacology and drug therapy in eye diseases; Basic Sciences; Primary and Secondary eye care; Patien Safety and Quality of Care Improvements. This journal is indexed on

Submit your manuscript here: http://www.dovepress.com/clinical-ophthalmology-journal

PubMed Central and CAS, and is the official journal of The Society of Clinical Ophthalmology (SCO). The manuscript management system is completely online and includes a very quick and fair peer-review system, which is all easy to use. Visit http://www.dovepress.com/ testimonials.php to read real quotes from published authors. 